\title{
Methods of Continuous Particle Sampling by Aircraft ${ }^{*}$
}

\author{
By A. Yamashita \\ Geophysical Institute, Tokyo University, Tokyo \\ (Manuscript received 29 June 1968, in revised form 29 January 1969)
}

\begin{abstract}
Three methods of continuous particle sampling are presented and their merits and defects are discussed one another. One is the replication method. This method had an advantage because it was possible to record ice crystals and water droplets simultaneously, however several precautions were required for the practical operation. Another is the water-blue method. This method was employed without difficulty, and the traces of water droplets were obtained very clearly. For the observation of clouds which had no hydrometeors this was better than the replication method. The other is the photomicrograph method. The use of this method was difficult in flight observations. Continuous airborn samplers were designed for these three methods.

From the practical point of view it is advisable to employ those two methods at the same time.
\end{abstract}

\section{1. tiortnInoduc}

The observations on the microstructure of clouds are one of the most important investigating works both for the fundamental cloud study and for the rainmaking experiment. In order to observe clouds in detail the author started aircraft observations in 1965 as a member of the rainmaking project in Japan. The project was promoted by the North Kanto Branch of Japanese Artificial Rainfall Research Cooperation from 1962 to 1966. The author undertook to design continuous airborn particle samplers that could be used on the Beechcraft C-18 S. Every sampler was designed so that cloud droplets and ice crystals might collide on $8-\mathrm{mm}$ motion picture film.

Among various collection methods, the author used three different methods, i.e. the plastic replica technique, the water-blue method and the photomicrograph method. Schaefer's formvar replication technique (Schaefer, 1956) has been employed by many investigators, and especially has been used by MacCready and Todd (1964) in an airborn continuous particle sampler. ouoŝeW and Tazawa (1965) have also employed the plastic replica method in their snow crystal sondes. The water-blue film method ( $\overline{\mathrm{O}} \mathrm{kita}, 1958)$ has been employed by some Japanese inves-

* Division of Meteorology, Contribution No. 169. tigators and has proved to be an excellent technique of contiouous sampling.

In the present paper the author shows particle samplers and describes the three sampling methods with the several interesting photographs of cloud

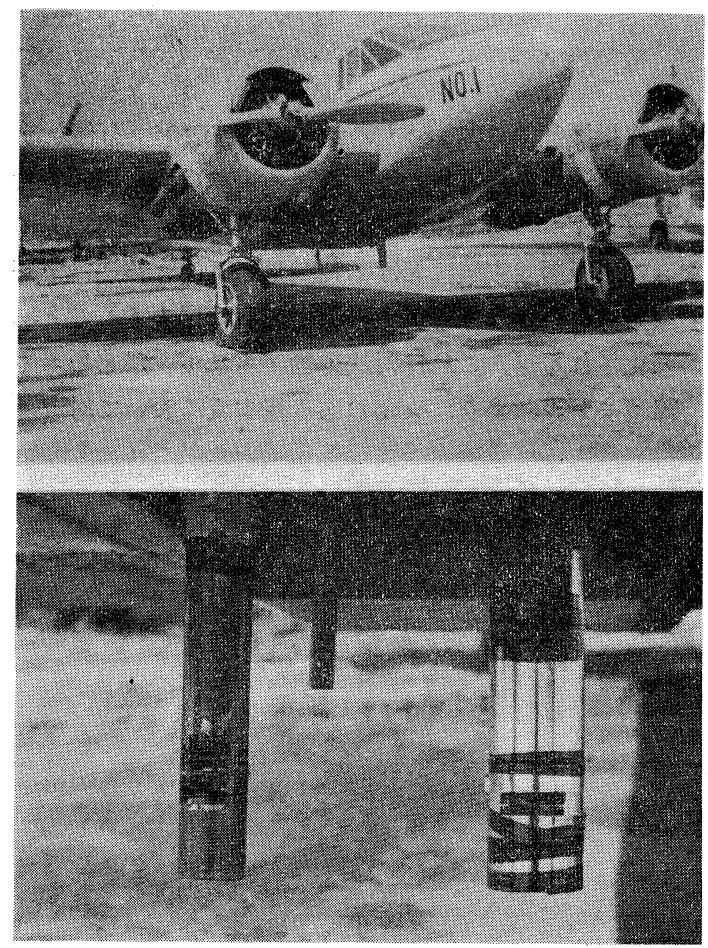

Fig. 1. Continuous cloud particle samplers mounted on the bottom of the fuselage (Beechcraft C-18 S). 


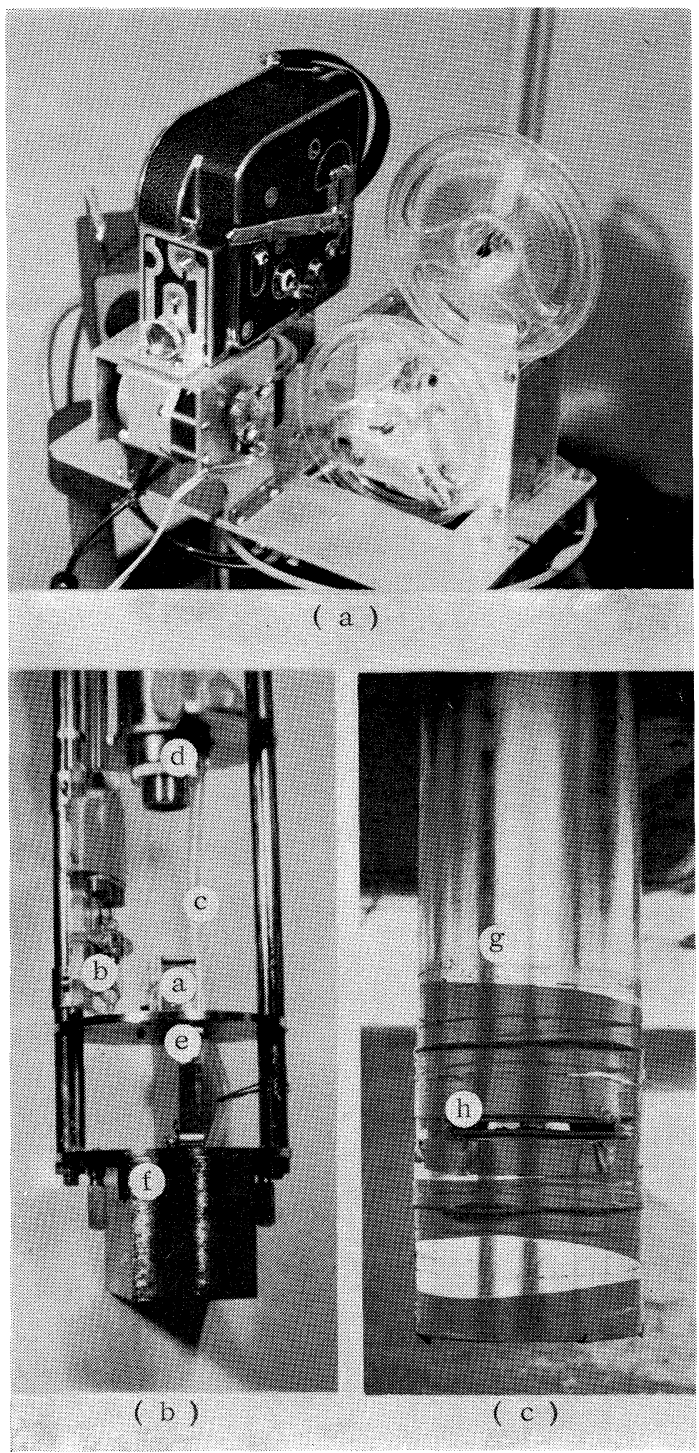

Figs. 2(a), 2(b) and 2(c). A continuous cloud particle sampler.

2(a) The apparatus takes $16-\mathrm{mm}$ photomicrographs (4 frames per second) and the reel feeds $300 \mathrm{ft}$ of $8-\mathrm{mm}$ film.

2(b) and 2(c)

a: condenser and film support

b: Xe-lamp

c: pipe for supplying replica solution or silicone oil

$\mathrm{d}$ : objective lens $(\times 2)$

e: $8-\mathrm{mm}$ motion picture film

f: $100 \mathrm{cc}$ tank

g: main pipe which covers the device shown in (b)

h: sampling opening

Side tube is attached at the rear of the main pipe. $8-\mathrm{mm}$ film is exposed at the center. particles.

\section{Instrument design}

The author designed and constructed several continuous samplers of cloud particles according to the requirement of the project. Fig. 1. shows the Beechcraft $\mathrm{C}-18 \mathrm{~S}$ equipped with two samplers. One of which is illustrated in Figs. 2(a), 2(b) and 2(c). This sampler was made for the photomicrograph method, but also could be used for the replication method and the water-blue method. Another sampler, illustrated in Fig. 3, was made for both the replication methd and the water-blue method.

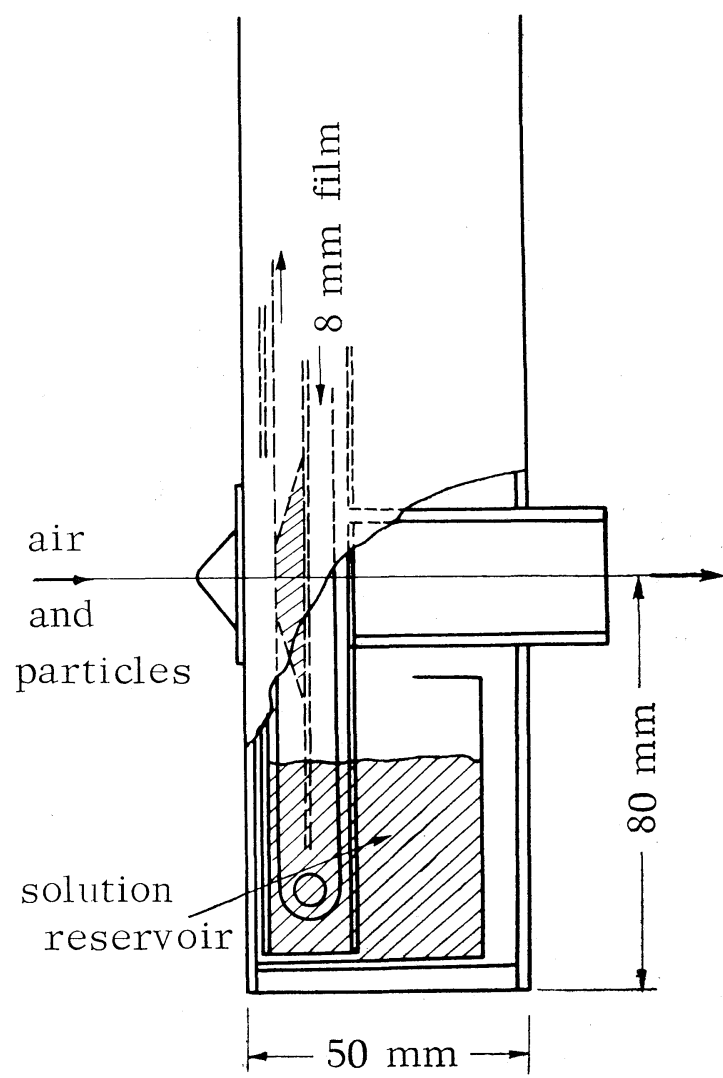

Fig. 3. Continuous cloud particle sampler of another type. The air and particles flow through the side tube.

These samplers use fixed 8-mm motion-picture film. A reel of the film is $300 \mathrm{ft}$ in length and it moves continuously at rates of $1 / 3,1$ or $3 \mathrm{~cm} /$ sec being selected depending on the density of droplets and ice crystals. In every case a sampler's tube sticks out from the bottom of the fuselage, and a rectangular opening on the 
sampler's tube is located at about $30 \mathrm{~cm}$ below the bottom of the fuselage. This distance was confirmed to be sufficient by the measurement of airspeed at the position of the sampler's opening. The sampler's tube consists of a main pipe and a side tube. The latter penetrates the former laterally (see Fig. 3) and has the sampler's opening mentioned above. This opening is the air inlet of the latter, and it's width can be controlled. The distance between the opening and the film is about $5 \mathrm{~mm}$.

The side tube plays a very important role in controlling the ambient air to be introduced. When the side tube does not penetrate $(2.5 \mathrm{~cm})$ in the rear of the main pipe the reverse air flow decreases the speed of particles that collide with the film. In this case it is possible to sample larger ice crystals without being destroyed (see Fig. 9), though the collection efficiency of small droplets is considerably decreased. As the main purpose had been to sample cloud droplets (larger than $5 \mu$ in diameter), the samplers were controlled as the air might flow through the side tube almost at the flight speed.

These different types of devices have several merits as described below.

(i) De-icing equipment is unnecessary at the sampler's opening except for very severe icing conditions. This was proved in a case of icing condition when icing of about $0.5 \mathrm{~cm}$ on the main pipe was experienced.

(ii) The samplers are made for the use of the three methods.

(iii) The samplers are made so simple that they can be modified for the purpose, i.e. sampling of ice crystals or sampling of droplets.

(iv) No drying apparatus is required even for the replication technique.

\section{Methods of cloud particle sampling}

Three different sampling methods were used for the continuous collection of cloud droplets and ice crystals.

\section{(i) The continuous replication method}

The replication method is a well-known technique that can be used in both laboratory and field experiments. The structure of ice crystals and other substances can be permanently preserved. A solution of formvar in ethylene dichloride ( $1-2 \%$ by weight) is used. When the sampler shown in Figs. 2 (a), 2(b) and 2(c) is used for the continuous replication method, a tank at the bottom of the probe is used as the reservoir of the solution. The solution can be supplied from the cabin when necessary. After dipped in the solution at the bottom, 8-mm film goes up to the side tube. As soon as the film is exposed to the ambient air, the solvent evaporates rapidly. Then droplets and ice crystals are covered by a thin formvar film, although they evaporate or sublime later. As the record of droplets and ice crystals is permanent, it can be examined by a microscope in the laboratory. Fig. 4 shows arranged 8-mm films on which ice crystals (a) and water droplets (b) are replicated.

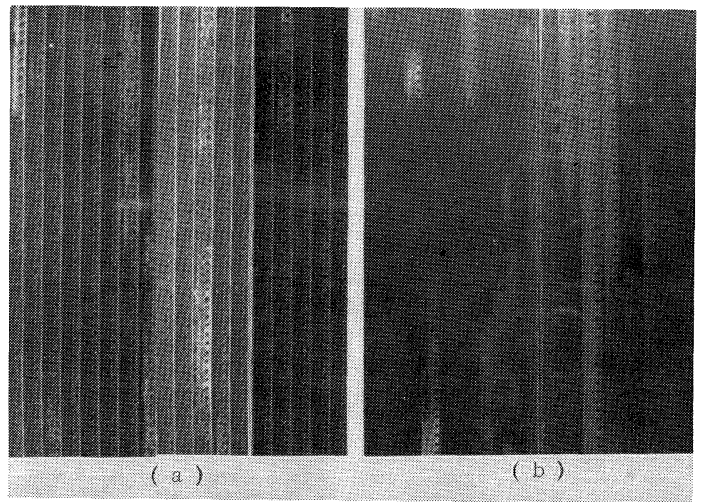

Fig. 4. Arranged $8-\mathrm{mm}$ film on which particles were replicated. (a: continuous record of replicated ice crystal clouds. b: that of supercooled clouds)

Examining the white portions under a microscope, the microphysical structure of the clouds is known.

(ii) The photomicrograph method

In order to study the microphysical structure of clouds, direct observations of cloud particles under a microscope, if possible, are desirable. This photomicrograph method is designed to take photomicrographs of collected particles as soon as possible on the airplane. The sampler is illustrated in Figs. 2(a), 2(b) and 2(c). A microscope, whose objective lens $(\times 2$ or 4$)$ is located at a close distance from the sampler's opening, is installed in the main pipe and it's eyepiece is about $35 \mathrm{~cm}$ apart from the objective lens. To avoid the effect of vibration of enlarged images, a Xe-stroboscopic illumination is used. Photographs are taken at the rate of four frames per second by a Bolex 16-mm camera.

(iii) The water-blue method

Water-blue, a kind of blue dyes, is an extremely 

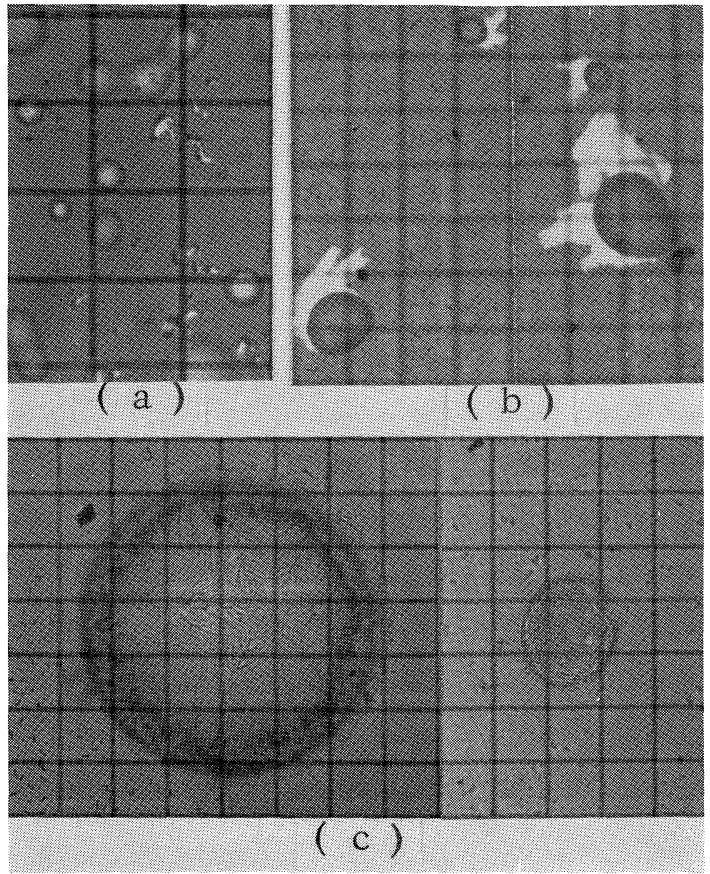

Fig. 5. Traces of ice crystals and water droplets on the water-blue film.

(a) water droplets $(50 \mu /$ mesh)

(b) ice crystals melted on the film ( $25 \mu /$ mesh)

(c) water drops which were frozen immediately after impaction and dried below the freezing temperature $(125 \mu /$ mesh).

water soluble chemicals. Commercial 8-mm motion-picture film is satisfactory for this method. If the film is processed by fixing solution, the film become transparent and one side of the film remains without gelatine layer. To manufacture a reel of $300 \mathrm{ft}$ film coated with water-blue dyes, a special apparatus (Fig. 6) is used. The film automatically moves through a bottle filled with the $2 \%$ water-blue aqueous solution, and is dried slowly by a heater. Thus the film which is uniformly coated with water-blue is obtained.

When a water droplet falls on the surface of the water blue film, a blue ring is produced on the water-blue surface. As it dries, there remains a clear trace of the droplet. It is found that the trace is more than three times as large as the original droplet in radius. It is possible to erase the dyes of the unnecessary side of the film when the film is examined by a microscope. The samplers shown in the last section can be used for the water-blue method, because this method needs only the system of carrying film continuously. Droplets evaporate immediately after the sampling.

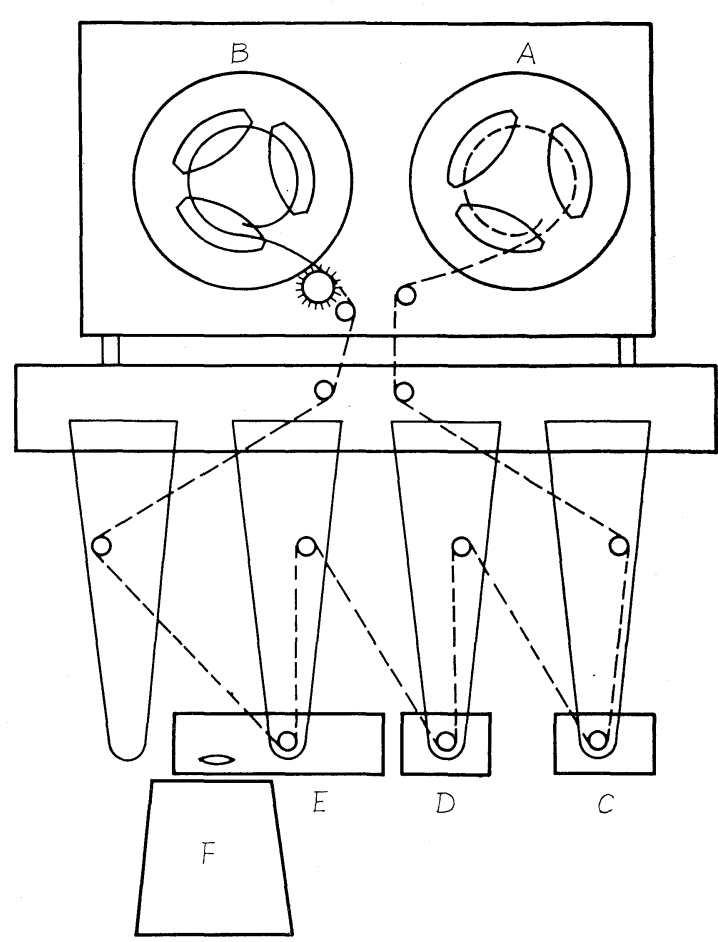

Fig. 6. A vertical cross section of the equipment for automatic treatment of 300 feet film.

(a) Preparation for water-blue film.

A: 8-mm commercial movie film whose emulsion is removed by fixer

B: treated film

E: $2 \%$ water-blue solution

F: magnetic stirrer

(b) Preparation for Farlow's film

C: $0.25 \% \mathrm{Ag}_{2} \mathrm{Cr}_{2} \mathrm{O}_{7}+2 \%$ polyvinyl-alcohol

D: $5 \% \mathrm{Ag} \mathrm{NO}_{3}$

E: distilled water

This method has two important merits. One of which is that the diameter of the recorded trace is about three times larger than the original diameter, and the other is that the process of recording droplets can be completed instantaneously after impaction. These enable us to examine water droplets smaller than $10 \mu$ in diameter easily without changing their diameter before completing the sampling. It is possible to distinguish the record of solid particles from that of liquid particles (see Fig. 5), although recorded ice crystals do not preserve their original crystal forms.

\section{Calibration and collection efficiency}

(a) Calibration for distortion of water droplets When the replication method or the photo- 
micrograph method is employed, the record of an ice crystal gives a crude measure of crystal size. However, it is not so easy to know the three dimensional structure, as the structure of recorded ice crystal is distorted by many factors such as the concentration of formvar solution, the ambient air temperature and the crystal size. By the water-blue method it is impossible to obtain a complete record of ice crystals.

If the impacting particle is a liquid droplet, the droplet will be distorted or broken according to the following conditions: the colliding speed, the size of a colliding droplet and the nature of film surface. A larger water drop which collides with the water-blue film breaks easilier than when the film is kept wet with the solution. Calibration curves shown in Fig. 7 were obtained by using atomizers and plastic syringes. In the case of the water-blue method the calibration curve is determined accurately after classified according to the

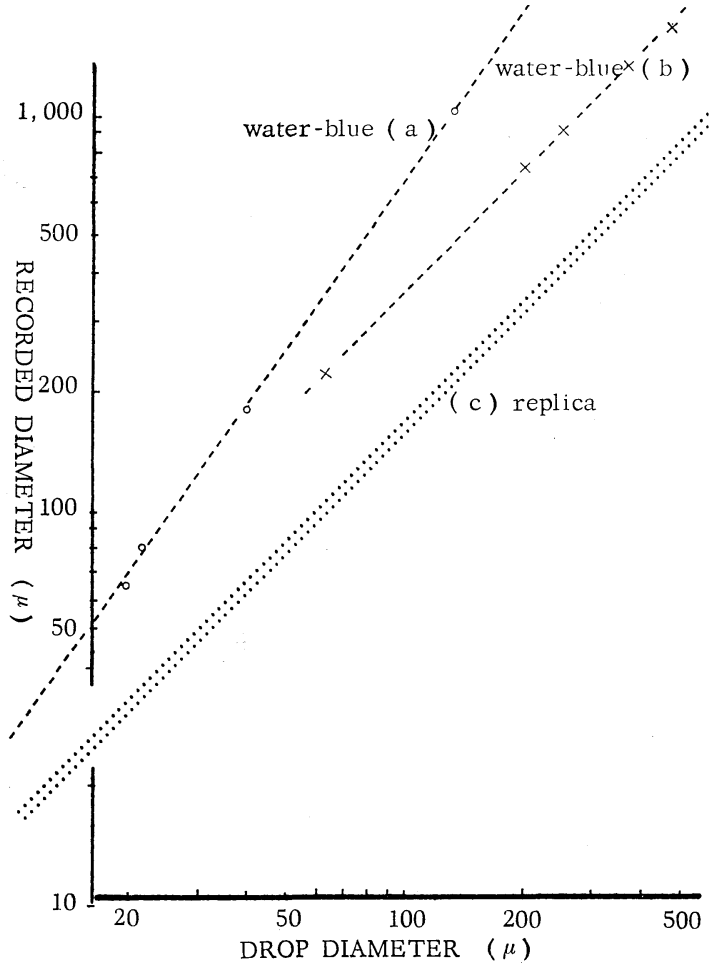

Fig. 7. Distortion calibration curves,

(a) when a drop collides on the surface of $8-\mathrm{mm}$ film at $40 \mathrm{~m} / \mathrm{sec}$,

(b) when a drop falls on 8-mm film at its terminal velocity,

(c) when a drop is replicated by using $2 \%$ formvar solution (distortion differs a little by drying conditions). impaction velocities. The calibration curve in the case of the replication method shown in Fig. 7 is approximate one because the calibration factor of a replicated droplet is influenced by the state of sampling surface. For example, evaporation of $\mathrm{C}_{2} \mathrm{H}_{4} \mathrm{Cl}_{2}$ changes the hardness of film surface and it will affect the calibration factor. The calibration curve in the case of the photomicrograph method is not shown in Fig. 7. It is estimated that there is not so much difference from that of the replication method by laboratory experiments.

\section{(b) Collection efficiency}

The speed of particles which collide with the film was assumed to be equal to the flight speed. It is possible to calculate collection efficiencies, if we apply the theory of Ranz and Wong (1952) assuming the $8-\mathrm{mm}$ film as a ribbon. In Table 1 a particular case of the calculated collection efficiency is shown. The mean flight speed of the aircraft is about $60 \mathrm{~m} / \mathrm{sec}$. The measured air speed at the film position was slightly less than $60 \mathrm{~m} / \mathrm{sec}$ although the measurements were made only a few times.

Table 1. Approximate values of calculated collection efficiency of water droplets against the $8-\mathrm{mm}$ film for the air speed $60 \mathrm{~m} / \mathrm{sec}$.

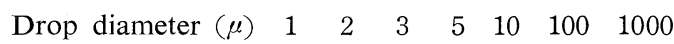

Calculated

collection

efficiency

(\%) $00 \begin{array}{lllll}0 & 40 & 70 & 90 & 100\end{array}$

100

The fact that the sampled droplets contained a number of small droplets less than $5 \mu$ in diameter even though the calculated collection efficiency is only about half of the magnitudes at the size $5 \mu$ in diameter, suggests that the sampler is capable and reliable for the purpose. In other words, the sampler is considered to be satisfactory for sampling particles larger than $5 \mu$ in diameter.

But when there are many droplets smaller than $5 \mu$ in diameter and when a reliable sampling of these smaller particles is required, the sampler should be modified to that the $1-2 \mathrm{~mm}$ film is used instead of the $8-\mathrm{mm}$ film. This was proved in our laboratory by testing collection efficiencies with $1 \mathrm{~mm}, 2 \mathrm{~mm}, 4 \mathrm{~mm}$ and $8 \mathrm{~mm}$ films. The water- blue method was tested with droplets down to a few microns. A difficulty in determining the collection efficiencies was found in the case of the replication method and the photo- 
micrograph method. That is, occasionally part of impacted particles on the film are blown off with the solution, and some of them are replicated on the back side of the film. The amount of such particles was estimated by comparing with the simultaneous sampling on the water-blue film.

When we hope to sample ice crystals with less deformation (Fig. 9) by the replication method, it is advisable to control a sampler so that the air speed is decelerated. This is possible by making the side tube not to penetrate the main pipe, then the reverse flow weakens the inflow through the sampler's opening. In this case smaller droplets are sometimes collected at the edge of the $8-\mathrm{mm}$ film.

\section{The results}

\section{(a) The replication method}

By means of this method we can observe coexisting ice crystals and supercooled droplets in a cloud at the same time. By making appropriate corrections it is possible to know the stage of glaciation of clouds quantitatively.

However, this method requires a great precaution for the operational use. Several unexpected facts came forth in our experience of the cloud observations. Evaporation of ethyrene dichloride cooled the surface of the film, and this caused the sampling of droplets difficult at the normal temperature. As long as $2 \%$ ethyrene dichloride was used, good replicas were obtained when the ambient air temperature was lower than $-10^{\circ} \mathrm{C}$.

When the air temperature was above the freezing temperature replicas were usually unsatisfactory. Ice crystals were sometimes replicated preserving their three dimensional forms when the film has been carrying sufficient replica solution, otherwise they are replicated only in two dimensional forms. Figs. 8-11 show the replicated cloud particles. In every figure one square of mesh sampled the volume $0.3 \mathrm{cc}$ of the air.

\section{(b) The photomicrograph method}

This method was proved to work well by laboratory tests, although, in flight observations some difficulty in focusing the microscope made the method unproductive during the project. Several records of supercooled cloud droplets had been obtained satisfactorily but ice crystals were not observed by this method even when they were found on the replicated film obtained simultaneously. Probably this was because ice crystals captured in the silicone oil were melted away unexpectedly fast by the dynamic heating.

\section{(c) The water-blue method}

This method was excellent for sampling water droplets, although it was hardly used for sampling ice crystals. The trace of a droplet was enlarged and was clear, but a tiny trace of ice crystal could not be distinguished from that of a droplet.

It was, however, possible to distinguish the trace of a snow crystal from that of a droplet. Rain drops splash at their collision with the water-blue film as shown in Fig. 12, as the film was kept dry.

\section{Application to sampling giant sea-salt nuclei}

Because the sizes of giant sea-salt nuclei are $1 \mu-10 \mu$ in diameter, it is possible to sample them on the $8-\mathrm{mm}$ film by using the same apparatus.

This attempt was started by observing the fact that a great number of dust particles were impacted on the replica film. The sampler's opening was set open as wide as possible $(40 \mathrm{~mm} \times 20 \mathrm{~mm})$ and the film speed was fixed at a rate of $1 / 3 \mathrm{~cm}$ per second. When the flight speed was 60 meter per second, the giant particles in 36 liters of the ambient air are sampled on the film every second. Estimation of collection efficiency of these particles is very difficult, but by examining the film after sampling, many small haloes, one micron in diameter, were found as the smallest. However, in practical purpose the $8-\mathrm{mm}$ film should be changed to a narrower film so that the collection efficiency is increased.

For detecting sea-salt nuclei, the technique developed by Farlow (1957) is employed. A fixed $8-\mathrm{mm}$ motion picture film was treated as $\mathrm{Cl}^{-}$ sensitive by the procedure shown in Fig. 6. As the surface of the film is coated with gelatin, the $\mathrm{Cl}^{-}$sensitive chemicals are stored in the gelatin layer.

Observations were carried out on the same aircraft through the project, and the results will be published in the near future.

\section{Conclusions}

The author succeeded in obtaining considerable amount of data of cloud particles during the aircraft observations. Because of shortage of the scheduled flight time, the first constructed samplers 

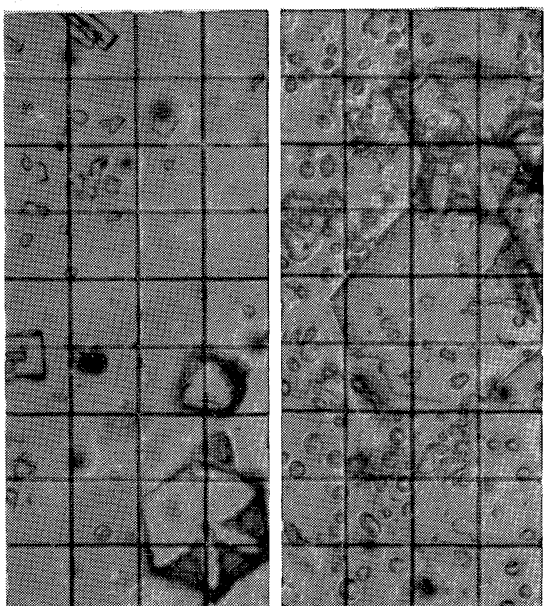

(a)
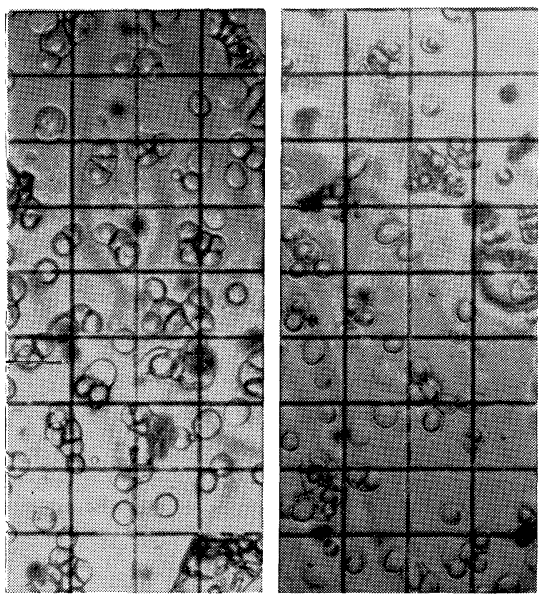

( c )
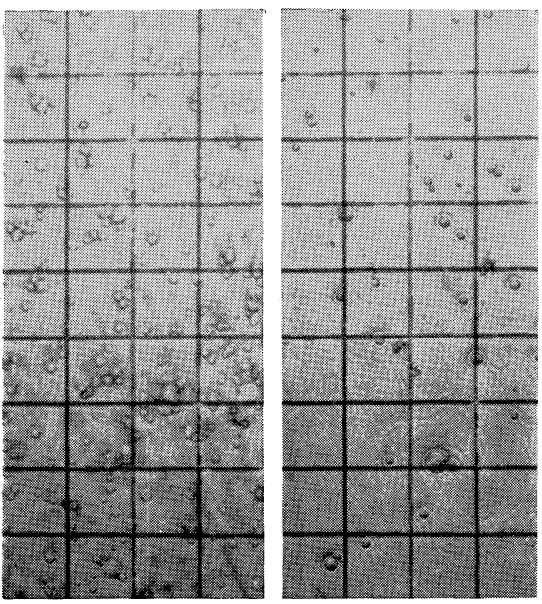

$(\mathrm{e})$
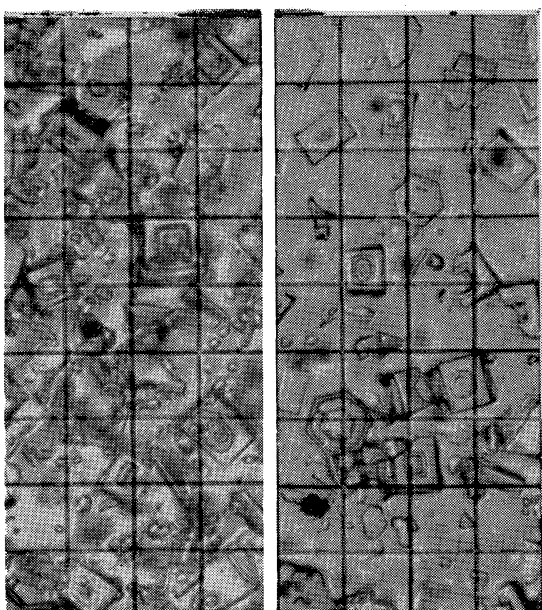

( $b)$
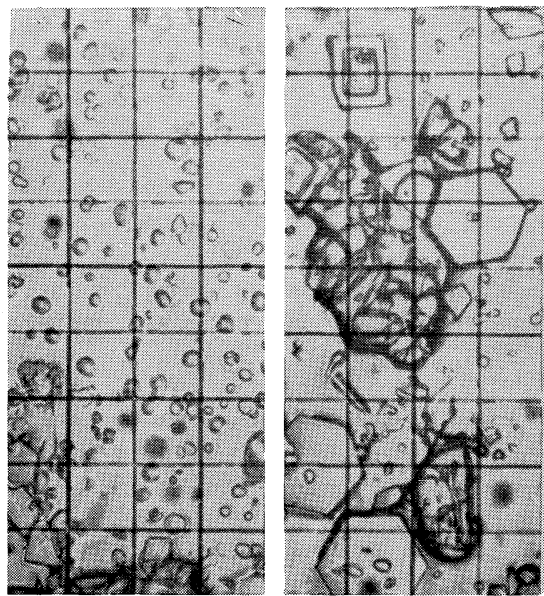

( d )
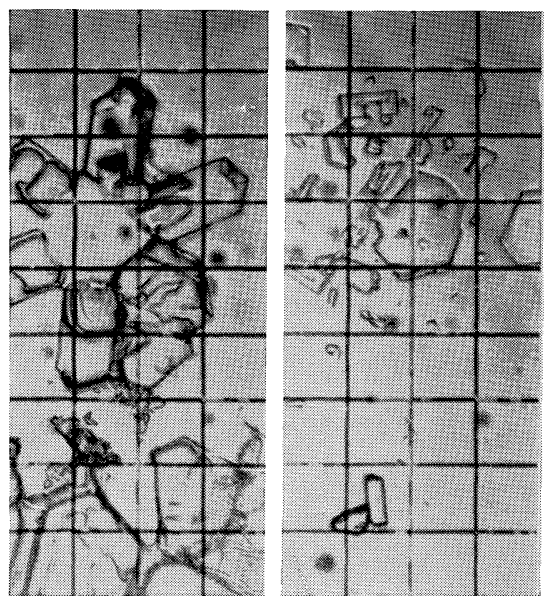

$(\mathrm{f})$

Fig. 8. Photomicrographs of replicated droplets and ice crystals

(1mesh $=48.8 \mu$, cumulus cloud, $-17^{\circ} \mathrm{C}, 9000 \mathrm{ft}$, Tsukuba district, 2 April 1965)

(a) (b) (c) (d); glaciating clouds (e); supercooled cloud in which a few snow crystals were falling as illustrated in (f). In every case the visual features of the clouds did not differ so much with each others. 

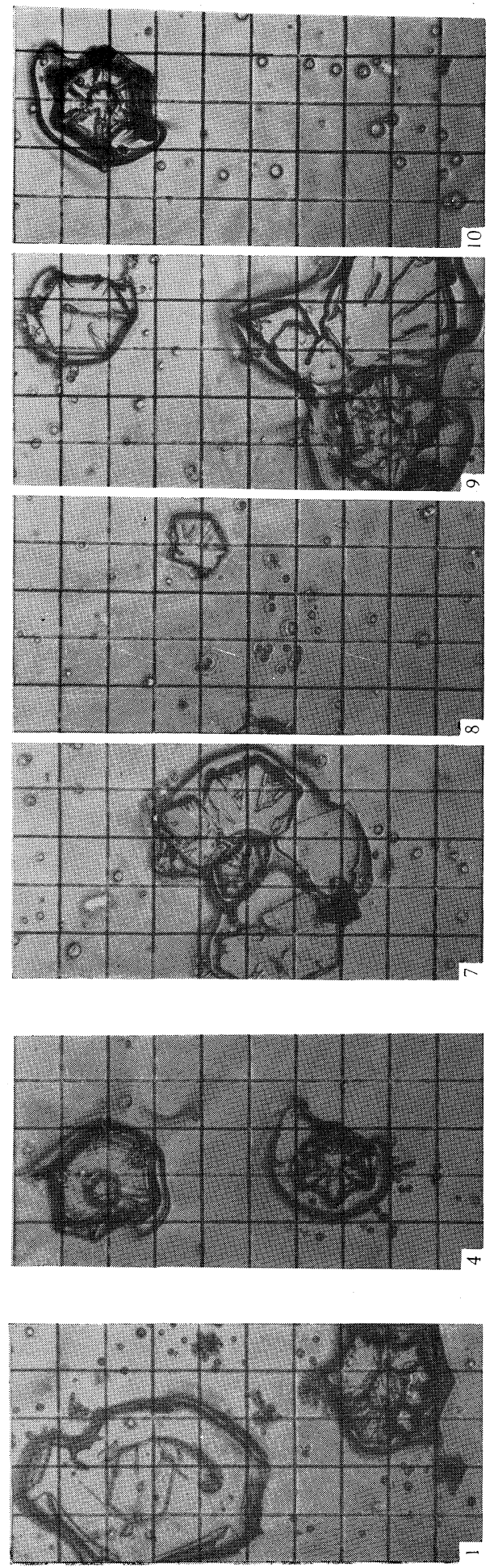
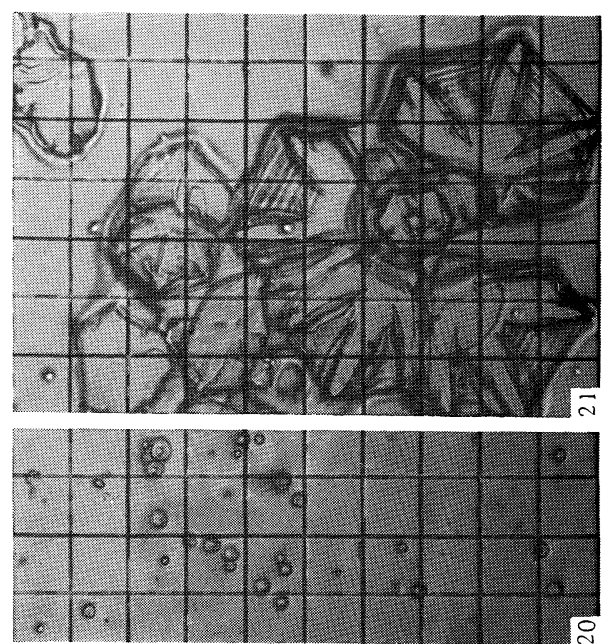

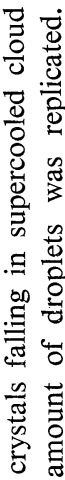

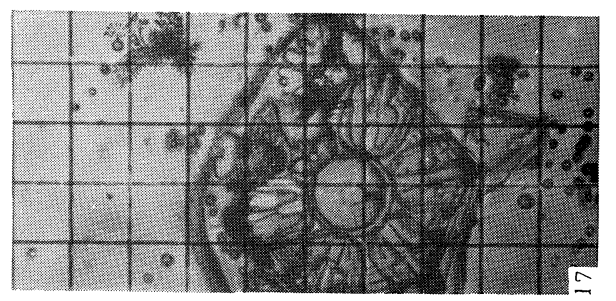

它吉焉 (5) $\dot{0}$ व 4 ต 政 금 范

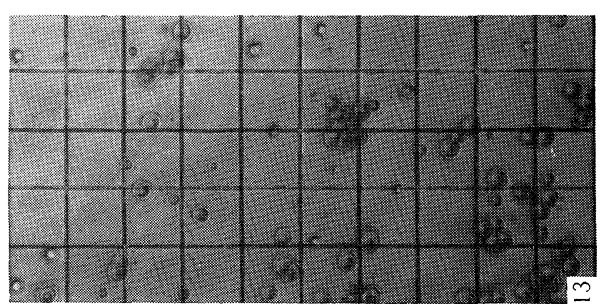
항 들 푱

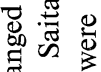
㱐 安远 。 a 诖员车
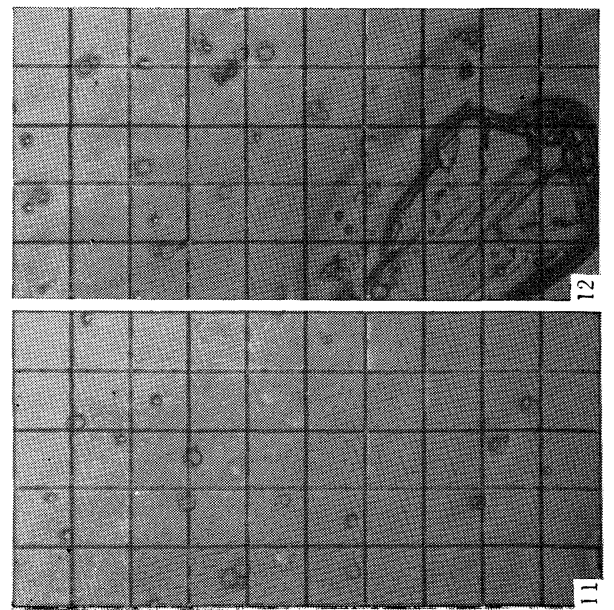

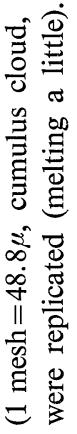



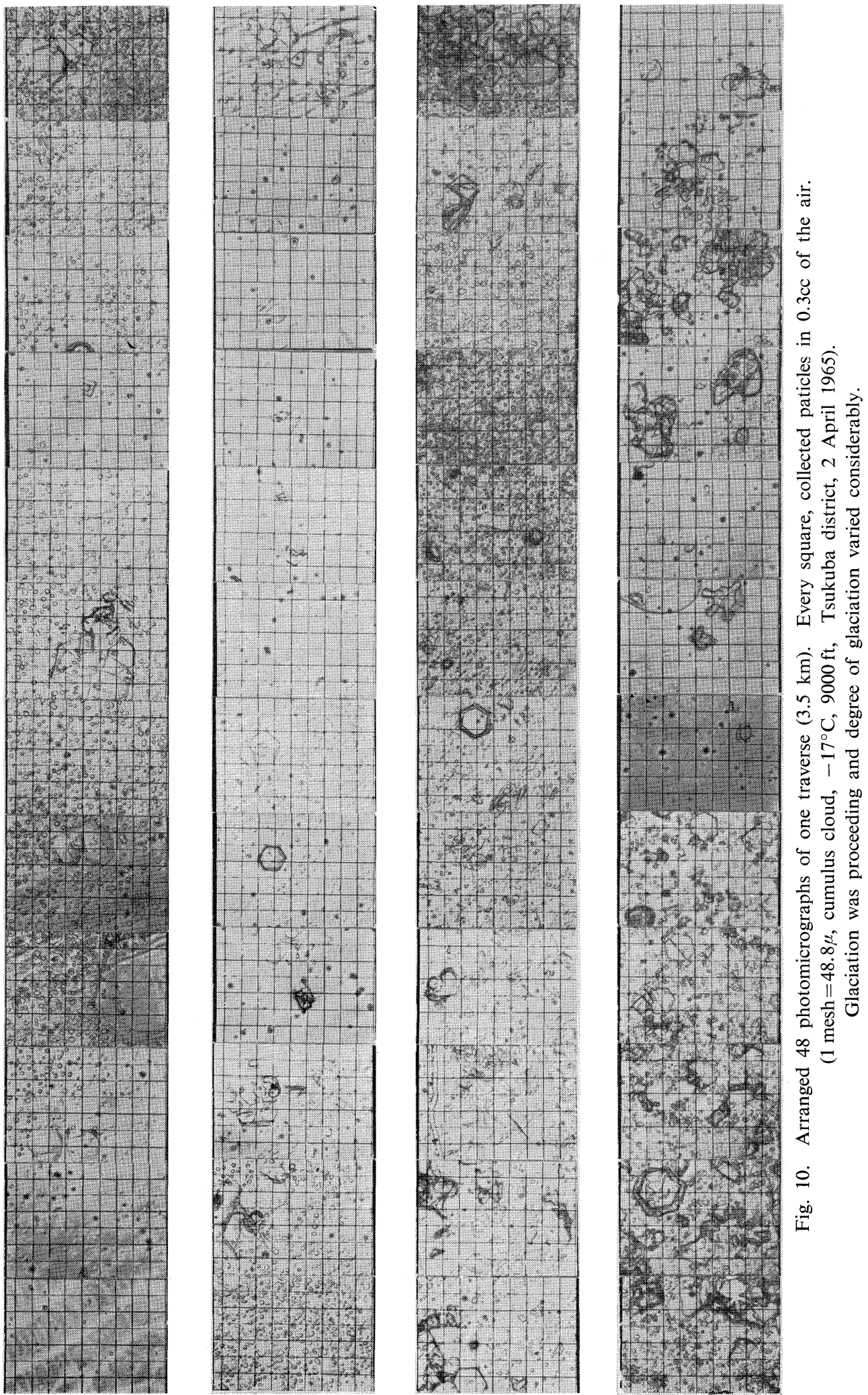

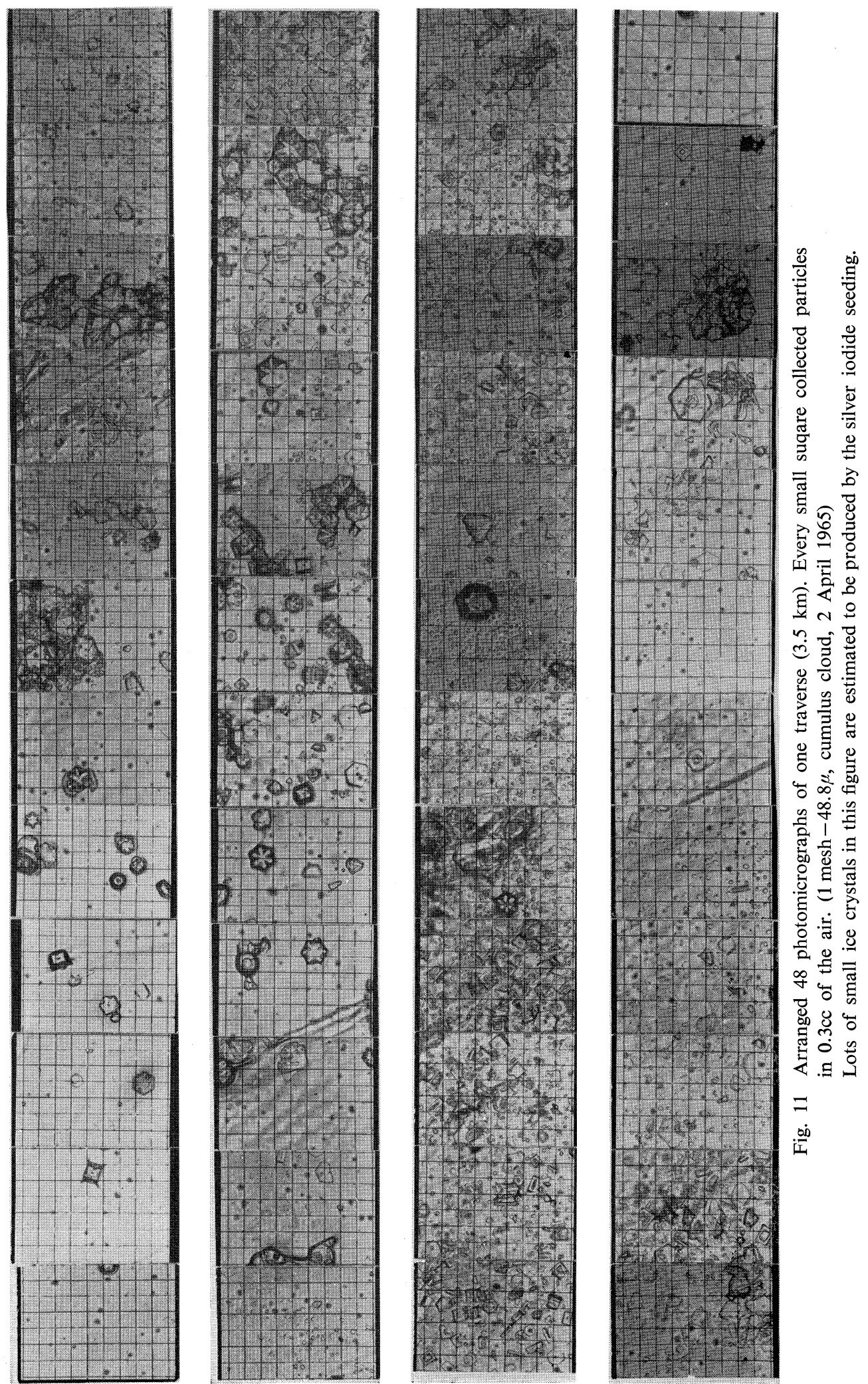


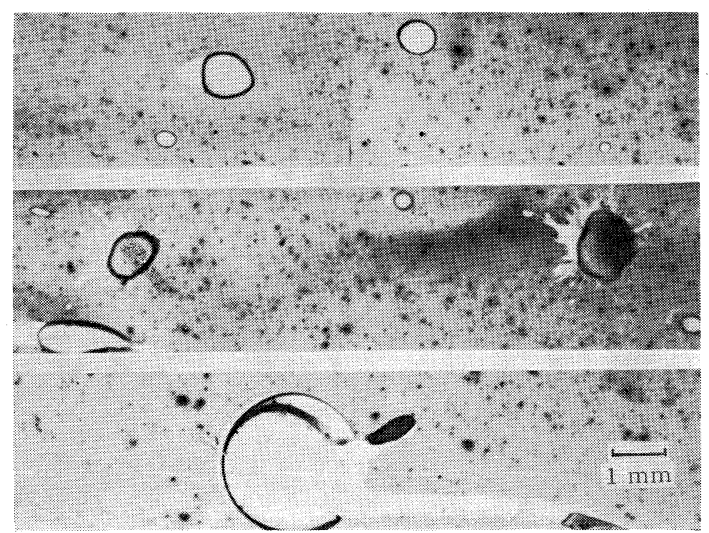

Fig. 12. Cloud drops and raindrops observed by the water-blue method. (15 October 1965)

were used practically and modified at every series of the flight for improvement. Through the modifications it was confirmed that one sampler which the penetrative side tube is adequate for the sampling of tiny cloud droplets, but the other sampler which has no penetrative tube in the rear side is good for the sampling of snow crystals.

The particles sampled by the replication or water-blue method are examined carefully by a microscope and, if necessary, photographed. Although this work for the analysis needs a great deal of labour, the photomicrograph method will be able to eliminate the labor great deal after the method is improved.

The characteristics of the three methods are itemized as follows.

\section{(a) The replication method}

1) It is possible to replicate droplets and ice crystals at the same time.

2) Concentration of the solution and even solvent should be changed depending on the purpose of observations. With the $2 \%$ solution alone good replicas are not expected for all kind of clouds. Such solution was very good at low temperatures $\left(-10 \sim-20^{\circ} \mathrm{C}\right)$.

3) In order to observe comparatively large ice crystals or snow crystals, it will be better that the apparatus is equipped with a drying accessory.

\section{(b) The water-blue method}

4) This method is the best for sampling water droplets, because the clear and enlarged traces are obtained.

5) There is no chance for droplets to flocculate on the film, because droplets make their traces in a moment of impaction.

6) The crystal forms of the sampled ice crystals are not revealed by the records but the records are distinguishable between droplets and crystals if they are not so small.

\section{(c) The photomicrograph method}

7) In laboratory photographs were successful. However, in flight observations it was found that the microscope system should have been improved so that the precise focusing was assured by rigid construction.

(d) The sampling of giant sea-salt nuclei

8) The majority of giant sea-salt nuclei larger than $1 \mu$ and some of the smaller sea-salt nuclei are collected on the $\mathrm{Cl}$ sensitive 8-mm film. However, narrower film should be used for this purpose.

9) For precise observation of $\mathrm{Cl}^{-}$nuclei, however, it is advisable to operate this method continuously with a parallel operation of the absolute and intermittent measurements.

For quantitative analysis of the data of droplets and ice crystals it was found through the project that at least two methods operated parallelly are greatly helpful because they overcome the defects that might come from the single method; actually the replication and water-blue methods were used at the same time as long as possible. Even when only the replication method is used, the operation of the plural samplers which have different collection efficiencies were of great value.

\section{Acknowledgements}

The author indebted to Prof. Syono and Dr. Ono for their constant encouragement and many helpful suggestions. Thanks are due to the members of the North Kanto Branch of Japanese Artificial Rainfall Research Cooperation, who supported the project and made aircraft observations possible. Thanks are also due to Prof. Yanai for his encouragement and careful reading of the present paper. 


\section{References}

Farlow, N.H., 1957: Quantitative determination of chloride ion in to $10^{-6} \sim$ to $10^{-12}$ (gram particles. Anal. Chem., 29, 883-885.

MacCready, P.B., Jr. and C. Todd, 1964: Continuous particle sampler. J. appl. Meteor., 3. 450-460.

Magono, C. and S. Tazawa, 1965: Observations of snow clouds by means of "Snow crystal sondes". Proceedings of the international conference on cloud physics, 231-235.

Ōkita, T., 1958: Water-blue film method for measurement of cloud and fog droplets. J. meteor. Soc. Japan, 36, 164-165.

Ranz, W.E. and J.B. Wong, 1952: Impaction of dust and smoke particles on surface and body collectors. Industr. Engng. Chem. (Industr.) 44, 1371.

Schaefer, V.J., 1956: The preparation of snow crystal replicas. Weatherwise, 9, 132-135.

\title{
航空機による雲粒及び氷晶の連続観測法について
}

\author{
山下晃 \\ 東京大学理学部地球物理学教室
}

航空機を用いて雲粒及び氷晶を連続観測するのに三つの方法を実際に用いた。装置は直接連続顕微鏡写真撮影が できるように設計したがこれは他の方法にる使用できるものである.

レプリカ法は雲粒及び承晶を同時にそのままレプリカとして保存するという点では最も優れているが, 常に良好な 結果を得るためには雲中の条件に合うよう微妙な調整が必要となる.ウォーターブルー法は過冷却水滴も含めた水滴 の捕捉には極めて良好な結果を示す．直接䫓微鏡写真撮影法は焦点合わせなど微妙な点はあるが, 解析が容易なこと など将来有力な方法となろう。 またレプレカ法とウォーターブルー法を併用することにより，各々が他の欠点を補い 実際向きの良好な観測を実行することができる. 